\title{
Factors contributing to men's grief following pregnancy loss and neonatal death: further development of an emerging model in an Australian sample
}

\author{
Kate Louise Obst ${ }^{1 *}$ (D), Melissa Oxlad ${ }^{1}$, Clemence Due ${ }^{1}$ and Philippa Middleton ${ }^{2}$
}

\begin{abstract}
Background: Historically, men's experiences of grief following pregnancy loss and neonatal death have been under-explored in comparison to women. However, investigating men's perspectives is important, given potential gendered differences concerning grief styles, help-seeking and service access. Few studies have comprehensively examined the various individual, interpersonal, community and system/policy-level factors which may contribute to the intensity of grief in bereaved parents, particularly for men.

Methods: Men $(N=228)$ aged at least 18 years whose partner had experienced an ectopic pregnancy, miscarriage, stillbirth, termination of pregnancy for foetal anomaly, or neonatal death within the last 20 years responded to an online survey exploring their experiences of grief. Multiple linear regression analyses were used to examine the factors associated with men's grief intensity and style.

Results: Men experienced significant grief across all loss types, with the average score sitting above the minimum cut-off considered to be a high degree of grief. Men's total grief scores were associated with loss history, marital satisfaction, availability of social support, acknowledgement of their grief from family/friends, time spent bonding with the baby during pregnancy, and feeling as though their role of 'supporter' conflicted with their ability to process grief. Factors contributing to grief also differed depending on grief style. Intuitive (emotion-focused) grief was associated with support received from healthcare professionals. Instrumental (activity-focused) grief was associated with time and quality of attachment to the baby during pregnancy, availability of social support, acknowledgement of men's grief from their female partner, supporter role interfering with their grief, and tendencies toward self-reliance.

Conclusions: Following pregnancy loss and neonatal death, men can experience high levels of grief, requiring acknowledgement and validation from all healthcare professionals, family/friends, community networks and workplaces. Addressing male-specific needs, such as balancing a desire to both support and be supported, requires tailored information and support. Strategies to support men should consider grief styles and draw upon fatherinclusive practice recommendations. Further research is required to explore the underlying causal mechanisms of associations found.
\end{abstract}

Keywords: Pregnancy loss, Neonatal death, Miscarriage, Stillbirth, Termination of pregnancy, Foetal anomaly, Men, Grief

\footnotetext{
* Correspondence: kate.obst@adelaide.edu.au

${ }^{1}$ School of Psychology, University of Adelaide, Adelaide, South Australia

Full list of author information is available at the end of the article

(c) The Author(s). 2021 Open Access This article is licensed under a Creative Commons Attribution 4.0 International License, which permits use, sharing, adaptation, distribution and reproduction in any medium or format, as long as you give appropriate credit to the original author(s) and the source, provide a link to the Creative Commons licence, and indicate if changes were made. The images or other third party material in this article are included in the article's Creative Commons licence, unless indicated otherwise in a credit line to the material. If material is not included in the article's Creative Commons licence and your intended use is not permitted by statutory regulation or exceeds the permitted use, you will need to obtain permission directly from the copyright holder. To view a copy of this licence, visit http://creativecommons.org/licenses/by/4.0/ The Creative Commons Public Domain Dedication waiver (http://creativecommons.org/publicdomain/zero/1.0/) applies to the data made available in this article, unless otherwise stated in a credit line to the data.
} 


\section{Background}

Despite continued global advancements in reproductive healthcare, both pregnancy loss and the death of a newborn baby within the first 28 days following birth (neonatal death) continue to be devastating realities for many families. The pervasive psychological and emotional impacts of parents' grief following pregnancy loss and neonatal death are now well-recognised [1-4]. Parents frequently report experiences of stigma, shame and disenfranchisement through minimisation of their loss from others, which can complicate their grief [5-9]. Men's experiences of pregnancy loss and neonatal death have been under-explored in comparison to women. However, a growing body of research has highlighted the importance of investigating men's perspectives, given potential gendered differences concerning grief, helpseeking and service access [10-17]. For example, quantitative studies comparing heterosexual couples' experiences following pregnancy loss and neonatal death suggest that men typically experience less intense and enduring levels of grief than women [18-23]. However, a smaller number of studies have found similar grief intensity between men and women [24, 25], or even higher levels of grief in men [26]. Broader research on grief also demonstrates potential differences in grief styles for men and women, with a general classification made between instrumental (action-focused coping) and intuitive (emotion-focused coping) styles [27]. Following pregnancy loss and neonatal death, studies suggest that men may engage in more instrumental grieving styles, which includes using activities, distraction or problem-solving approaches to grief, as opposed to intuitive styles which use emotion-focused approaches including outward displays of crying, talking about grief, or seeking social support [9, 16, 28-35].

Our recent systematic review of men's grief following pregnancy loss and neonatal death emphasised the importance of examining grief from a holistic, socioecological perspective to understand the varied factors which can contribute to men's experiences (see Fig. 1) [36]. At the individual level, factors contributing to men's grief include demographic elements (e.g., age,

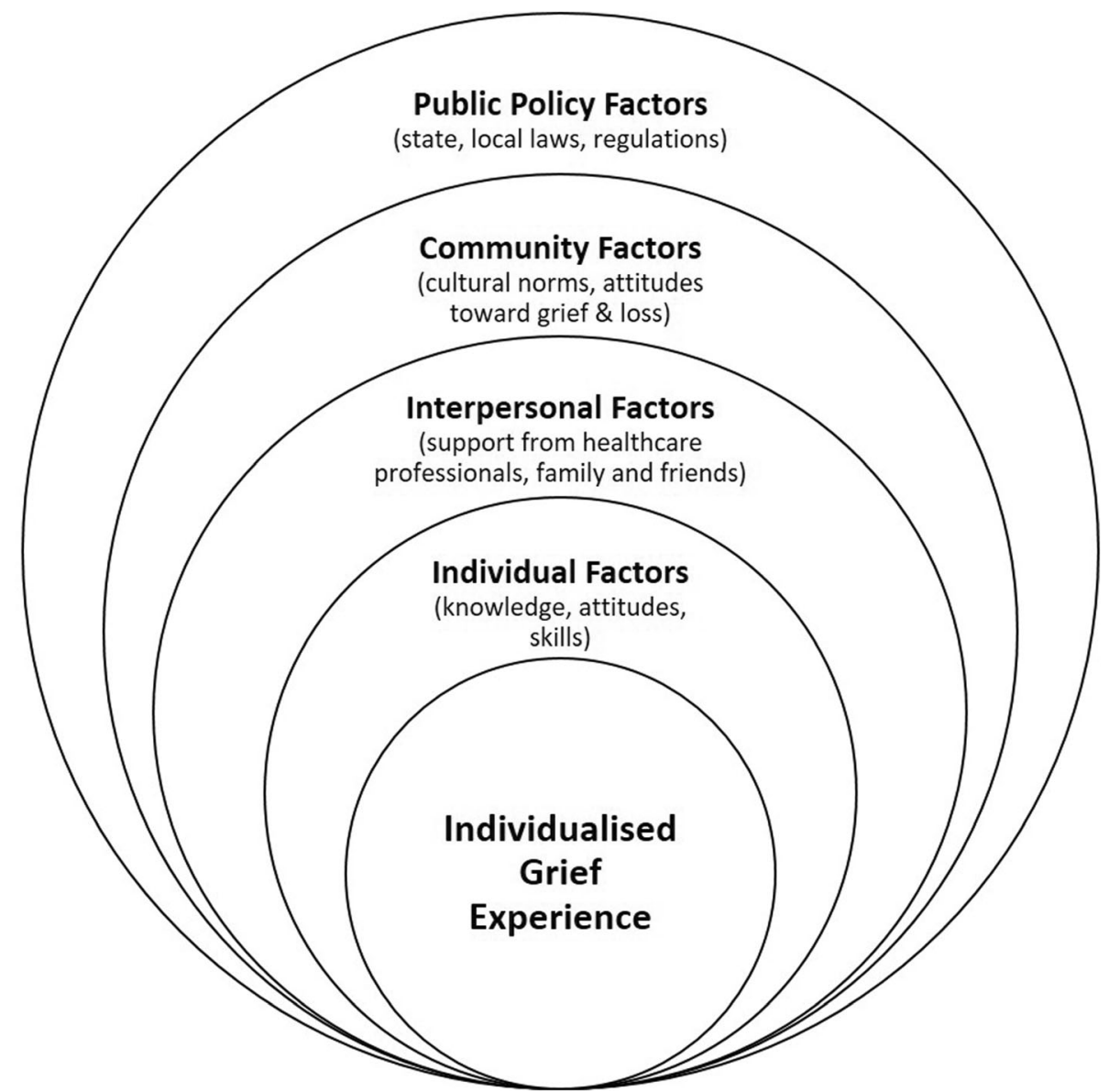

Fig. 1 Socioecological model of men's grief. Socioecological model of men's grief, demonstrating the factors contributing to men's grief following pregnancy loss and neonatal death at the individual, interpersonal, community and public policy levels. This image was generated by the authors for a previous publication [36] 
religion, ethnicity), pregnancy loss/neonatal death history and number of living children. Regardless of gestational/newborn age of the baby, previous research also suggests that attachment is a particularly strong predictor of men's grief intensity. Although early quantitative research measured 'attachment' using increasing gestational age or whether or not men viewed an ultrasound of their developing baby [20, 22, 23, 37, 38], qualitative studies have suggested that a broader exploration of prenatal attachment (e.g., through everyday interactions with the developing baby) may be more important in determining the intensity of men's grief response $[10,12,13,16,30,32,34]$.

At the interpersonal level, men's interactions with others have been found to have implications for shaping their grief experience. Qualitative studies have pointed to the importance of whether men felt acknowledged as a grieving father from family, friends and healthcare professionals; where there was a lack of recognition for men as grieving fathers, grief intensity worsened [9, 10, 12, 33, 39]. Throughout the qualitative literature, heterosexual men's role primarily as a 'supporter' to their female partner has remained a consistent and dominant theme. This role has often been reported as hindering men's expressions and experiences of grief $[10,12,13,16,33,34$, 40]. However, a smaller number of studies have also suggested potential benefits of this role, particularly among people who are instrumental grievers, for whom this role could provide purpose $[30,41]$.

At the broader community level, qualitative studies have also consistently noted that men's experiences are shaped by social attitudes concerning the legitimacy of parents' grief, as well as gendered expectations surrounding how (or if) men should openly display emotion $[9,10,12,16,29]$. These expectations were related to masculinity ideals, which often prescribed being strong or stoic in the face of loss [12, 13, 16, 32, 33].

Finally, at the system/policy level, experiences within the healthcare system following pregnancy loss or neonatal death have been established as fundamental to shaping bereaved parents' grief experience $[4,9,42]$. For some men specifically, the context of woman-centred care in hospital (when applicable to the type of loss) has been found to be isolating and can worsen grief outcomes $[10,12,34]$. Also in relation to systems issues, research indicates that policies regarding bereavement leave within workplaces typically differ for men and women, with some men reporting less access to paid leave following their loss than women [10, 29, 33]. As many men have reported returning to work soon after pregnancy loss or neonatal death, bereavement leave policies may play a role in grief outcomes [36].

In addition to the research on factors relating to men's grief, several studies have explored various factors relating to grief intensity in women following pregnancy loss and neonatal death [43-50] and couples [23, 38, 51-53]. Most of these studies have examined individual, interpersonal, community or system-related factors separately, rather than together in a single model. Similarly, with the exception of Riggs et al. [17] who explored relationships between grief, psychological distress, stigma, help-seeking and social support, the studies outlined above concerning factors related to grief for men have also focused on specific variables such as the duration of pregnancy or viewing an ultrasound image. Importantly, no previous research has considered factors relating to different styles of grief, which may be important, given that studies have suggested gendered grieving styles [27]. Using the socioecological model of men's grief developed in our previous systematic review as a basis [36], this study aimed to quantify and further explore the factors which contribute to men's grief, with a particular focus on previously under-explored determinants. Specifically, we sought to determine the factors associated with grief intensity following pregnancy loss and neonatal death, as well as the factors associated with intuitive and instrumental grief styles.

\section{Methods \\ Participants}

Ethical approval for the study was granted by the University of Adelaide Human Research Ethics Committee on the 5th of June, 2019 (approval code HREC-2018273). Participants were Australian men who had experienced the loss of a baby at any stage of gestation to miscarriage, ectopic pregnancy, medical termination of pregnancy for nonviable foetal anomaly (TOPFA), stillbirth or neonatal death. Inclusion criteria were that participants were aged 18 years of age or older and had experienced pregnancy loss or neonatal death in Australia within the last 20 years. Although potentially open to recall bias, this timeframe was selected to maximise the potential pool of eligible respondents. Of 277 participants who commenced the survey, 228 completed all items and were included in the final sample reported here (completion rate $=82 \%$ ). There were no apparent differences between completers and non-completers on demographic characteristics. At the time of survey completion, participants were aged between 19 and 60 years $(M=36, S D=7.4)$. At the time of loss, they were aged between 18 and 58 years $(M=32, S D=5.5)$. See Table 1 for a summary of participant characteristics at the time of survey completion.

\section{Procedure}

A web-based survey was developed by the authors (see Additional file 1), hosted by the online platform SurveyMonkey. This survey was developed for the purposes of 
Table 1 Participant characteristics

\begin{tabular}{|c|c|c|}
\hline & Category & $N(\%)$ \\
\hline \multirow[t]{2}{*}{ Ethnicity } & Australian & $194(85 \%)$ \\
\hline & Other $^{a}$ & $34(15 \%)$ \\
\hline \multirow[t]{5}{*}{ Sexual orientation } & Heterosexual & $224(98 \%)$ \\
\hline & Bisexual & $3(1.5 \%)$ \\
\hline & Homosexual & $0(0 \%)$ \\
\hline & Transgender & $0(0 \%)$ \\
\hline & Rather not answer & $1(0.5 \%)$ \\
\hline \multirow{4}{*}{$\begin{array}{l}\text { Highest level of } \\
\text { education }\end{array}$} & High School & $54(24 \%)$ \\
\hline & $\begin{array}{l}\text { Technical and Further } \\
\text { Education (TAFE)/Trade }\end{array}$ & $83(36 \%)$ \\
\hline & Undergraduate Degree & $58(25 \%)$ \\
\hline & Postgraduate Degree & $33(15 \%)$ \\
\hline \multirow[t]{5}{*}{ Marital status } & Married & $186(82 \%)$ \\
\hline & In a relationship & $35(15 \%)$ \\
\hline & Divorced & $1(0.5 \%)$ \\
\hline & Separated & $4(1 \%)$ \\
\hline & Never married/single & $2(2 \%)$ \\
\hline \multirow[t]{4}{*}{ Area of residence ${ }^{b}$} & Major city & $131(58 \%)$ \\
\hline & Inner regional & $64(28 \%)$ \\
\hline & Outer regional & $28(12 \%)$ \\
\hline & Remote/very remote & $4(2 \%)$ \\
\hline \multirow[t]{4}{*}{ Number of losses } & One & $138(61 \%)$ \\
\hline & Two-three & $15(7 \%)$ \\
\hline & Four-five & 47 (21\%) \\
\hline & Six or more & $28(12 \%)$ \\
\hline \multirow{5}{*}{$\begin{array}{l}\text { Loss type reflected } \\
\text { on for the survey }\end{array}$} & Ectopic pregnancy & $5(2 \%)$ \\
\hline & $\begin{array}{l}\text { Termination of pregnancy } \\
\text { for foetal anomaly (TOPFA) }\end{array}$ & $30(13 \%)$ \\
\hline & Miscarriage & $69(30 \%)$ \\
\hline & Stillbirth & 77 (34\%) \\
\hline & Neonatal death & 47 (21\%) \\
\hline \multirow[t]{6}{*}{ Time since loss } & Less than one year & $65(28 \%)$ \\
\hline & $1-2$ years & $40(18 \%)$ \\
\hline & $3-5$ years & $59(26 \%)$ \\
\hline & $6-10$ years & $43(19 \%)$ \\
\hline & $11-15$ years & $10(4 \%)$ \\
\hline & $16-20$ years & $11(5 \%)$ \\
\hline
\end{tabular}

${ }^{\mathrm{a}}$ Other ethnicities reported by participants include: European (8\%), Asian (2\%) and New Zealander (2\%)

${ }^{\mathrm{b}}$ Based on Australian Bureau of Statistics classification of remoteness

the current study, and has not been published elsewhere. Extensive consultation and piloting was undertaken with members of a reference group (including Australian fathers and mothers who had experienced pregnancy loss/ neonatal death, grief counsellors and pregnancy loss/ neonatal death support workers and researchers) as part of the broader program of research to form the final survey. Initially, preliminary discussions were held with individual members of the reference group concerning the types of measures used and questions to be asked, in line with the socioecological model of men's grief. With this feedback, the first author (KO) drafted a full survey. In the two successive rounds of piloting, members of the reference group reviewed updated drafts of the survey in full and were invited to provide suggestions for revision. Although major concepts remained the same, the ordering, inclusion and wording of questions and final measures selected, were edited and refined according to feedback to ensure both sensitivity and ease of understanding.

Potential participants were invited to take part in the survey via advertisements through Australian pregnancy loss and neonatal death support and advocacy organisations. These included Pillars of Strength, Bears of Hope, Sands Australia, Still Aware, Miracle Babies Foundation, SIDS and Kids SA, and the Australian Perinatal Loss Centre. Following ethics approval, these organisations were contacted by the first author via email or telephone to discuss the study. All organisations agreed to share a study flyer and information through either social media platforms (primarily Facebook), newsletters, and/or organisation websites.

The study flyer contained brief information about the survey and the online survey link, which opened to a covering page with a preamble providing potential participants with detailed information about the study. After reading the study preamble, participants provided passive consent, a method of consent approved by the University of Adelaide Human Research Ethics Committee, by choosing to commence the survey and submit their responses. In recognition of the sensitivity of the topic and potential for participants to experience emotional distress in reflecting on their experience of loss, a comprehensive distress protocol was developed and articulated to participants. This included providing contact details for national pregnancy loss telephone support lines at the beginning and end of the survey. No concerns regarding participant distress were raised during the research.

The survey took approximately $30 \mathrm{~min}$ to complete. Depending on participant responses, skip logic was incorporated to hide questions which were irrelevant to individual experiences, often resulting in a shorter completion time $(M=22 \mathrm{mins})$. The number of items/questions presented to participants who completed they survey therefore ranged between 110 and 130. Participation in the survey was voluntary and anonymous. Data collection occurred between June and August 2019. Data were exported from the online SurveyMonkey platform 
and stored on a secure university-approved network at the University of Adelaide.

\section{Measures}

Participants completed questions relating to demographic characteristics (age, ethnicity, education, occupation, sexual orientation, marital status, religion and postcode), along with questions about their pregnancy and loss history. Definitions for the death of a baby during pregnancy or shortly following birth vary, with gestational cut-offs for classification differing between countries. In Australia, a miscarriage is defined as the death of a baby in-utero before 20 weeks' gestation and occurs for approximately $20 \%$ of pregnancies [54]. In 1$2 \%$ of pregnancies, an ectopic pregnancy occurs when the fertilised ovum implants outside of the uterus, most commonly in the fallopian tube [54-56]. A stillbirth is defined as the loss of a baby from at least 20 weeks' gestation or over $400 \mathrm{~g}$ in weight, occurring for 7.1 per 1000 births [57]. Neonatal death refers to the death of a newborn infant within the first 28 days of life and occurs for 2.5 per 1000 live births [57]. A congenital anomaly is diagnosed in approximately one in 22 pregnancies in Australia [58]. National data on TOPFA is not collected in Australia. However, it has been estimated that most parents whose pregnancies are deemed life-limiting or affected by chromosomal anomalies elect to medically terminate; usually before, or soon after, 20 weeks of gestation [59]. Where more than one type of pregnancy loss or neonatal death had been experienced, participants were asked to reflect on only one type of their choice for the remainder of the survey. An option to comment on other losses was provided at the end of the survey. Participants then completed a mix of questions developed by the authors as well as standardised measures.

In line with the literature on the 'supporter role' relating to men's grief $[10,12,13,16,36,40,60]$, two author-developed measures were included to determine the extent to which men perceived this to be their role, and whether they felt it interfered with their grief. Participants responded to these questions on a five-point Likert scale from $1=$ strongly disagree to $5=$ strongly agree. Higher scores indicated that men perceived their role to be a supporter to their female partner and family after the loss and that their supporter role had a larger impact on their ability to grieve. Scales were also developed to determine the extent to which participants felt their grief was recognised by others, namely: their partner, family, friends, health professionals, and the wider community. For these, participants responded on a fivepoint Likert scale from $1=$ not at all to $5=$ extremely. Higher scores were indicative of higher levels of recognition for their grief. Participants were also asked a series of questions about their experiences of returning to work, including whether they were offered leave, and what type of leave they were offered (detailed results published elsewhere; see [103]). If they had contact with a hospital as part of their loss experience, they were also asked about the extent to which they felt included (from $1=$ not at all to 5 = extremely; where higher scores indicated a greater sense of inclusion), and whether they were offered information on grief for fathers (yes/no). The six included standardised measures are outlined below.

\section{Paternal Antenatal Attachment Scale (PAAS)}

A modified version of the Maternal Antenatal Attachment Scale (MAAS), the PAAS assesses both the quality and strength of the subjective experience of the father's attachment to the developing baby [61, 62]. Comprising 16 items forming two subscales (Quality of Attachment and Time in Attachment), the PAAS is answered using five-point Likert scales, where higher scores indicate stronger attachment to the baby. Although only a small number of previous studies have used the PAAS, relationships have been found with related measures including relationship quality, mental health, increasing gestational age, and father identity [63, 64]. Previous research also supports the reliability and validity of the PAAS, with reports of high internal consistency (Cronbach's alpha $=0.83$ ) [62]. For this study, the final question of the scale "If the pregnancy was lost at this time (due to miscarriage or other accidental event) I expect I would feel ..." was omitted, given that participants had experienced a pregnancy loss or neonatal death. Internal consistency of this 15 -item version in this study was also high (Cronbach's alpha $=0.83$ ).

\section{Perinatal Grief Scale-33 (PGS-33)}

Designed to quantify bereaved parents' grief based on emotional responses, the PGS-33 assesses thoughts and feelings associated with perinatal loss [65]. The overall scale comprises three subscales: Active Grief (outward expressions of grief including crying, sadness and missing the baby), Difficulty Coping (difficulties with daily activities and relating to others) and Despair (feelings of hopelessness and worthlessness). Participants rate each item on a five-point Likert scale ranging from $1=$ strongly agree to $5=$ strongly disagree, with higher scores indicating more intense grief. The PGS-33 is the most common grief scale used among the perinatal loss literature and has been extensively evaluated, with psychometrically sound properties reported (including Cronbach's alphas between 0.92 and 0.96) [66, 67]. Internal consistency for the full measure was also high in this study (Cronbach's alpha $=0.94)$. Although questions remain surrounding the accuracy of using the PGS among men, as it may not be sensitive to instrumental 
grieving styles [36], given a current lack of alternative grief measures specifically for men following pregnancy loss/neonatal death, we decided that in conjunction with the Grief Patterns Inventory (described below), this was the best available measure to adopt.

\section{Grief Patterns Inventory-Revised (GPI-10)}

A measure developed to assess an individuals' general grieving pattern, the GPI indicates a tendency toward either an instrumental or intuitive grieving style. The original measure comprised 24 items containing true-false responses; however, a revised version containing ten items (five items each for the instrumental and intuitive styles) was used in the current study to reduce respondent burden $[68,69]$. A pilot study of the 10 -item version reported moderate inter-correlations between subscale items, along with a significant negative correlation between the intuitive and instrumental subscales $(r=$ -.525) [68]. Although alpha coefficients were not reported for the 10-item version, research demonstrates acceptable internal consistency for the original version (Cronbach's alphas ranging between 0.71 and 0.76) [70]. In this study, a similar level of internal consistency was found (Cronbach's alpha $=0.71$ ). Items are rated on a five-point Likert scale from $1=$ strongly disagree to $5=$ strongly agree, with instrumental items reverse-scored. As such, potential total scores ranged from 10 to 50, with lower scores indicating a more instrumental style, and higher scores indicating a more intuitive style. As applied previously [69], categorisation of grief styles was made as follows: $10-23=$ instrumental; $24-36=$ blended; $37-50=$ intuitive.

\section{Crisis Support Scale (CSS)}

The CSS is a measure of social support received from family and friends following a traumatic event (in this case, pregnancy loss or neonatal death). Comprising seven items relating to the availability of others, emotional support, and practical help, respondents rate their agreement to the items on a seven-point Likert scale, ranging from $1=$ never to $7=$ always. In the original scale, participants responded to two time points: just following the event (T1) and the present time (T2). However, for this study, participants were only asked to provide responses for the support that was available to them most of the time following their loss. Higher scores indicate higher levels of social support. Validation studies indicate robust psychometric properties for the scale across a range of trauma populations, including bereaved parents of infants (with Cronbach's alphas ranging between 0.67 and 0.82 ; in this study, Cronbach's alpha was $0.69)[71]$.

\section{Conformity to Masculine Norms Inventory (CMNI)}

Developed based on Mahalik's model of gender role conformity, the CMNI assesses the extent to which an individual male does or does not conform to the actions, thoughts, and feelings reflected by broad masculinity norms [72, 73]. The original scale consists of 144 items forming 11 distinct factors. However, to reduce participant response burden, only one subscale comprising five items from the overall measure was included for this study, to determine respondents' tendencies toward SelfReliance. This subscale was chosen in line with previous literature which suggests men often feel the need to hide their grief from others, preferring to cope in isolation $[10,12,13,16,29,33]$. The questions included: "I never ask for help", and "It bothers me when I have to ask for help". Respondents rated the degree to which they agreed with these statements on a four-point Likert scale from 1 = strongly disagree to $4=$ strongly agree, with higher scores indicating a stronger tendency toward being self-reliant. Widely used in the literature, many studies have reported construct validity for the CMNI, along with discriminant validity between its subscales and high internal consistencies (Cronbach's alpha of 0.85 for the Self-Reliance subscale; in this study, Cronbach's alpha was 0.86) [73].

\section{Male Role Norms Inventory-Short Form (MRNI-SF)}

A measure of masculinity ideology developed by Levant et al. [74], the original MRNI comprised 57 items with seven subscales. In 2011, a 39-item revised form was proposed, followed by a 21-item short-form in 2013. For this study, the Toughness subscale from the MRNI-SF was used, as items closely aligned with the recurrent theme of needing to be 'strong' or 'tough' reported by men following pregnancy loss in previous literature [10, $13,16,32,33]$. The subscale comprises three items, including: "When the going gets tough, men should get tough". Responses are given on a seven-point Likert scale from 1 = strongly disagree to 7 = strongly agree. Higher scores indicate higher levels of endorsement toward traditional masculine ideology [75]. Research has demonstrated sound psychometric properties for the MRNI-SF, including subscale alphas ranging from 0.79 to 0.90 [75]. In this study, Cronbach's alpha for the 3item Toughness subscale was 0.61 .

\section{Data analysis}

Analyses were performed using SPSS Statistics (V.25). Data were summarised using descriptive statistics and relationships between the variables were assessed using generalized linear modelling with a multiple stepwise approach, including a backward elimination method outlined by Sainani [76]. The generalised linear model is a flexible form of usual linear regression used to compare 
the effect of several variables which may have error distributions other than a normal distribution on a continuous outcome variable. Using a link function to relate the response variable to the linear model, it provides a maximum likelihood estimation of the model parameters rather than assuming a linear-response model [77]. As recommended for multivariable modelling [78], a priori selection of variables for this study was guided by the socioecological model of men's grief identified in our previous systematic review [36]. Given the nested form of the socioecological model, variables were entered into the regression models in four (stepwise) stages. Assumptions required for generalised linear modelling were assessed prior to analysis; all necessary assumptions were satisfied. Individual-level variables were entered first, and a backward elimination process was carried out until all variables were statistically significant at the 0.5 level as recommended by Harrell [78]. This process was repeated with each of the interpersonal, community and policy/system-level variables until all had been entered into the model (see Table 2 for the variables entered at each level).

While we acknowledge the debates surrounding the use of $p$-values in making decisions regarding variable selection $[79,80]$, the cut-off for inclusion of 0.5 (rather than the traditional choice of $a=0.05$ ) used for variable selection in this study is considered to be a reasonable and conservative estimate for a multivariable model [78]. Also, to reduce the risk of bias from sparse data, backward elimination is recommended to achieve a suitable number of degrees of freedom for the model given the number of observations in the study; a general rule is that degrees of freedom should be no more than the number of observations divided by ten to reduce the risk of bias [78]. Without the use of backward elimination, our models would have violated this rule. Ultimately, our approach resulted in a suitable number of degrees of freedom for each model in this study.

\section{Statistical power}

There are no consistent rules for sample size requirements in linear regression [81]. However, various general recommendations have been made about minimum sample size, or sample size depending on the number of independent variables included in the model. While one general rule recommends a minimum of 100 participants regardless of the number of independent variables [82], others suggest 50 plus the number of independent variables [83], or at least 100 for less than three independent variables or $300-400$ for nine or 10 independent variables [84]. Tabachnick and Fidell also suggested a sample size of $50+8 k$, where $k$ is equal to the number of independent variables [85]. Employing recommendations to consider a minimum sample size of 50 plus the number of independent variables $[83,85]$, with a sample size of 228 and the number of independent variables included in the models at any one stage not exceeding 16 , the current study had sufficient statistical power.

\section{Results \\ Descriptive statistics}

Descriptive statistics for continuous variables are presented in Table 3. Overall, grief scores were high, with the average score sitting above the minimum cut-off considered to be a high degree of grief according to population norms (cut-off $=91$ ) [67]. In particular, the highest mean grief scores occurred on the Active Grief subscale (indicating feelings of sadness and missing the baby), and the lowest scores occurred on the Despair subscale (indicating feelings of worthlessness and hopelessness). On average, men experienced the lowest average grief following early losses ( $<20$ weeks' gestation); however, the standard deviation $(S D)$ was high and the mean score still represented a high degree of grief. The average grief score following late loss ( $\geq 20$ weeks' gestation) was the highest, followed by neonatal death. Again, however, the ranges were wide and SDs were high,

Table 2 Variables entered into the multiple linear regression analyses

\begin{tabular}{|c|c|}
\hline Stage entered into the model & Variables \\
\hline Stage 1 (individual variables) & $\begin{array}{l}\text { Loss type; Grief style ; PAAS Time in Attachment; PASS Quality of Attachment; Whether men attended } \\
\text { obstetric appointments; Whether men viewed an ultrasound image of their baby; Age at time of loss; } \\
\text { Ethnicity; Importance of religion; Number of previous losses; Number of surviving children at time of loss }\end{array}$ \\
\hline Stage 2 (interpersonal variables) & $\begin{array}{l}\text { Marital satisfaction; Extent of agreement to the statement: "My role following the loss was to support } \\
\text { my partner and family"; Extent of agreement to the statement: "I was unable to grieve, because I was } \\
\text { too busy supporting everyone else"; Total CSS score; Extent of acknowledgement from partner; Extent } \\
\text { of acknowledgement from family; Extent of acknowledgement from friends }\end{array}$ \\
\hline Stage 3 (community variables) & $\begin{array}{l}\text { Extent of acknowledgement from community; CMNI Self-Reliance subscale total score; MRNI Toughness } \\
\text { subscale total score }\end{array}$ \\
\hline Stage 4 (policy/system variables) & $\begin{array}{l}\text { Extent of acknowledgement from healthcare professionals; Degree to which participants felt included in } \\
\text { the hospital ; Whether employment leave was offered to men; Whether other psychosocial supports } \\
\text { were offered to men }\end{array}$ \\
\hline
\end{tabular}

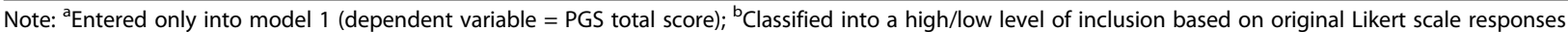
(scores $1-3=$ low level of inclusion and 4-5 = high level of inclusion) 
Table 3 Descriptive statistics for continuous variables

\begin{tabular}{|c|c|c|c|c|}
\hline & $N$ & Mean & Range & $S D$ \\
\hline \multicolumn{5}{|l|}{ Total PGS score according to loss type } \\
\hline Early loss ( $<20$ weeks' gestation) ${ }^{a}$ & 82 & 93.4 & $47-152$ & 23.2 \\
\hline Late loss ( $\geq 20$ weeks' gestation) ${ }^{b}$ & 90 & 109.7 & $65-158$ & 19.8 \\
\hline Neonatal death & 46 & 107.0 & $65-151$ & 23.4 \\
\hline \multicolumn{5}{|l|}{ Total PGS score according to time since loss } \\
\hline Last 5 years & 156 & 103.2 & $49-158$ & 23.3 \\
\hline $6-10$ years ago & 42 & 104.8 & $47-151$ & 23.6 \\
\hline $11-20$ years ago & 20 & 98.2 & $65-141$ & 21.1 \\
\hline \multicolumn{5}{|l|}{ Individual-level variables } \\
\hline Age at loss (in years) & 225 & 32 & $17-58$ & 5.5 \\
\hline Time since loss (in years) & 228 & 4.3 & $0-20$ & 55 \\
\hline PGS total score & 218 & 103 & $47-158$ & 23.0 \\
\hline Active Grief subscale & 222 & 42.8 & $22-55$ & 6.3 \\
\hline Difficulty Coping subscale & 226 & 32.7 & $12-53$ & 9.8 \\
\hline Despair subscale & 226 & 27.2 & $11-54$ & 9.1 \\
\hline GPI - Intuitive & 225 & 19.6 & $8-24$ & 3.8 \\
\hline GPI - Instrumental & 227 & 17.6 & $5-25$ & 4.1 \\
\hline PAAS total score & 224 & 58.5 & $35-72$ & 8.0 \\
\hline PAAS Quality of Attachment subscale & 224 & 30.1 & $15-35$ & 3.6 \\
\hline PAAS Time in Attachment subscale & 228 & 19.7 & $5-28$ & 4.5 \\
\hline \multicolumn{5}{|l|}{ Interpersonal-level variables } \\
\hline Marital satisfaction at time of loss & 228 & 4.8 & $1-5$ & 0.6 \\
\hline Acknowledgement from partner & 228 & 3.9 & $1-5$ & 1.0 \\
\hline Acknowledgement from friends & 228 & 3.0 & $1-5$ & 1.1 \\
\hline Acknowledgement from family & 228 & 3.4 & $1-5$ & 1.2 \\
\hline CSS total score & 226 & 30.9 & $10-48$ & 8.3 \\
\hline Extent of agreement to: "My role following the loss was to support my partner and family" & 228 & 4.5 & $1-5$ & 0.8 \\
\hline Extent of agreement to: "I was unable to grieve, because I was too busy supporting everyone else" & 228 & 3.3 & $1-5$ & 1.3 \\
\hline \multicolumn{5}{|l|}{ Community-level variables } \\
\hline Acknowledgement from community & 228 & 2.1 & $1-5$ & 1.1 \\
\hline CMNI Self-Reliance subscale & 227 & 13.1 & $5-20$ & 3.1 \\
\hline MRNI Toughness subscale & 228 & 11.7 & $3-21$ & 3.7 \\
\hline \multicolumn{5}{|l|}{ Policy/system-level variables } \\
\hline Perceived extent of inclusion in the hospital & 189 & 3.6 & $1-5$ & 1.3 \\
\hline Acknowledgement from healthcare professionals & 228 & 2.7 & $1-5$ & 1.3 \\
\hline
\end{tabular}

ancludes ectopic pregnancy, miscarriage and TOPFA at less than 20 weeks' gestation

' Includes TOPFA and stillbirth at or over 20 weeks' gestation

indicating substantial variation in scores. Although the mean grief score was slightly lower for losses which occurred more than 10 years ago, there was a negligible association between time since loss and total grief scores $(\mathrm{F}(2,215)=.556, p=.574)$.

According to the GPI, average scores were significantly higher for the intuitive grief items compared to the instrumental grief items $(t(223)=4.611, p<.001)$. Men's total reported attachment to their baby was also generally high. Specifically, scores on the Quality of Attachment subscale were also significantly higher than those on the Time in Attachment subscale $(t(223)=38.9, p<.001)$.

Men felt the most acknowledgement for their grief from their partners, and the least acknowledgement from the wider community and healthcare professionals. Average agreement concerning the extent to which men 
felt they had a supporter role following the loss was high. However, agreement regarding the extent to which this role impacted men's ability to grieve was in the mid-range.

\section{Multiple linear regression models}

Multiple stepwise linear regression analyses were performed to determine which variables were associated with total grief (PGS total score), intuitive grief, and instrumental grief (GPI scores). Results for the three resulting models are presented below.

\section{Model 1: Total grief (PGS)}

Fourteen variables were below the 0.5 significance cutoff for inclusion in the final model for men's total grief scores, and seven of these had confidence intervals which did not contain zero (see Table 4). When adjusting for all other factors, men who lost a baby to miscarriage had a mean total PGS score of 16.5 points less than men who experienced a neonatal death. However, the confidence interval was wide, indicating a low level of precision in this estimate; this may be due to large variability in grief scores across loss types. Narrow confidence intervals, indicating higher levels of certainty, were observed for history of loss, time in attachment and overall support. Specifically, a higher number of previous pregnancy losses/neonatal deaths were associated with higher levels of grief, as were lower levels of overall support and increased time in attachment. Higher grief scores were also associated with lower levels of acknowledgement of grief from friends, as well as higher levels of agreement to the statement: "I was unable to grieve, because I was too busy supporting everyone else". However, the opposite was observed for acknowledgement from family, with men experiencing higher levels of grief with more acknowledgement. Again, though, confidence intervals were wide for these factors, indicating less certainty in the precision of the estimates.

Table 4 Multiple stepwise linear regression for PGS total score $(n=204)$

B

Variables

Loss focus

Ectopic pregnancy

TOPFA

Miscarriage

Stillbirth

Neonatal death

PAAS Time in Attachment subscale

Age at loss (in years)

Number of previous losses experienced

Marital satisfaction at the time of loss

Agreement to the statement: My role following the loss was to support my partner and family"

Agreement to the statement: "I was unable to grieve, because I was too busy supporting everyone else"

CSS total score

Extent of acknowledgement of grief from family

Extent of acknowledgement of grief from friends

Extent of acknowledgement from wider community

CMNI Self-Reliance

Workplace leave

Employment leave offered

Employment leave not offered

Did not inform employer of loss

Other workplace supports

Other supports offered

Other supports not offered

Did not inform employer of loss

\begin{tabular}{|c|c|c|c|c|}
\hline-4.09 & $(-18.78-10.60)$ & 7.49 & -.02 & .59 \\
\hline-6.41 & $(-14.08-1.26)$ & 3.91 & -.09 & .10 \\
\hline-16.48 & $(-23.01--9.95)$ & 3.33 & -.32 & $<.001$ \\
\hline 1.42 & $(-4.57-7.42)$ & 3.06 & .03 & .64 \\
\hline Ref & - & - & - & - \\
\hline 2.10 & $(1.60-2.61)$ & .26 & .44 & $<.001$ \\
\hline 0.39 & $(-0.05-8.37)$ & .23 & .09 & .09 \\
\hline 1.84 & $(0.18-3.49)$ & .85 & .10 & .03 \\
\hline-3.60 & $(-7.01-0.19)$ & 1.74 & -.10 & .04 \\
\hline-2.48 & $(-5.45-0.49)$ & 1.52 & -.09 & .10 \\
\hline 3.45 & $(1.45-5.45)$ & 1.02 & .21 & $<.01$ \\
\hline-.69 & $(-1.12--0.26)$ & 1.02 & -.24 & $<.01$ \\
\hline 3.39 & $(0.74-6.05)$ & 1.36 & .16 & $<.01$ \\
\hline-2.89 & $(-5.75--0.03)$ & 1.46 & -.13 & .05 \\
\hline-1.92 & $(-4.44-0.59)$ & 1.28 & -.11 & .13 \\
\hline .47 & $(-0.32-1.25)$ & .40 & .07 & .25 \\
\hline 21.44 & $(-11.11-53.99)$ & 16.61 & .47 & .19 \\
\hline 21.12 & $(-11.61-53.86)$ & 16.70 & .39 & .21 \\
\hline Ref & - & - & - & - \\
\hline-23.42 & $(-56.45-9.60)$ & 16.85 & -.49 & .17 \\
\hline-25.75 & $(-59.17-7.66)$ & 17.05 & -.58 & .13 \\
\hline Ref & - & - & & - \\
\hline
\end{tabular}


Model 2: Intuitive grief (GPI)

Thirteen variables met the 0.5 significance cut-off for inclusion in the final model for intuitive grief, although only one had a confidence interval which did not contain zero (see Table 5). Lower reported levels of acknowledgement from healthcare professionals were associated with higher intuitive grief scores.

\section{Model 3: Instrumental grief (GPI)}

Sixteen variables met the 0.5 significance cut-off for inclusion in the final model for instrumental grief; of which, eight had confidence intervals which did not contain zero (see Table 6). While increased quality of attachment was associated with a slight decrease in men's grief scores, higher scores on time in attachment were associated with an increase in grief. Although the supporter role itself was not associated with instrumental grief, men who perceived their supporter role as interfering more with their ability to grieve experienced higher levels of instrumental grief. Lower grief scores were associated with higher levels of total support. More specifically, higher perceived acknowledgement of men's grief from their partner was associated with a reduction in grief. Higher endorsement of self-reliance masculine ideals was associated with higher levels of instrumental grief. Finally, men who did not inform their workplace of their loss had higher levels of grief in comparison to those who did; this was regardless of whether workplace leave was offered to those who informed their employer. However, the confidence intervals for these workplace factors were wide, indicating a degree of caution should be exercised regarding the strength of these relationships.

\section{Discussion}

Main findings and implications

This study, using multivariable linear regression analyses, explored relationships between men's grief following pregnancy loss/neonatal death and a range of previously identified socioecological factors [36]. In relation to the severity of men's grief (as measured by the PGS), men who had experienced previous losses, lower levels of social support and more time bonding with their baby during pregnancy had higher grief scores. Men who had lower marital satisfaction, little acknowledgement of their grief from friends, felt as though their

Table 5 Multiple stepwise linear regression for intuitive grief $(n=210)$

\begin{tabular}{|c|c|c|c|c|c|}
\hline & $B$ & $95 \% \mathrm{Cl}$ & SE $B$ & $\beta$ & $p$ \\
\hline \multicolumn{6}{|l|}{ Variables } \\
\hline \multicolumn{6}{|l|}{ Ultrasound viewing } \\
\hline Ultrasound viewed during pregnancy & 1.5 & $(-0.01-3.03)$ & .77 & .15 & .05 \\
\hline Ultrasound not viewed during pregnancy & Ref & - & - & - & - \\
\hline \multicolumn{6}{|l|}{ Ethnicity } \\
\hline Other & 1.17 & $(-0.12-2.35)$ & .60 & -.13 & .05 \\
\hline Australian & Ref & - & - & - & - \\
\hline PAAS Quality of Attachment subscale & .10 & $(-0.02-0.22)$ & .06 & .12 & .09 \\
\hline Age at loss (in years) & .07 & $(-0.02-0.16)$ & .05 & .07 & .10 \\
\hline Number of surviving children at loss & -.20 & $(-0.67-0.27)$ & .24 & -.05 & .40 \\
\hline Agreement to the statement: "My role following the loss was to support my partner and family" & -.37 & $(-0.90-0.15)$ & .27 & -.08 & .16 \\
\hline CSS total score & .06 & $(0.4--0.01)$ & .04 & .15 & .10 \\
\hline Extent of acknowledgement for grief from family & .26 & $(-0.24-0.76)$ & .26 & .11 & .31 \\
\hline CMNI Self-Reliance subscale & -.14 & $(-0.29-0.02)$ & .08 & -.12 & .08 \\
\hline MRNI Toughness subscale & -.05 & $(-0.17-0.06)$ & .06 & -.07 & .37 \\
\hline \multicolumn{6}{|l|}{ Workplace leave } \\
\hline Employment leave offered & 4.98 & $(-1.2-11.16)$ & 3.16 & .73 & .11 \\
\hline Employment leave not offered & 4.93 & $(-1.3-11.19)$ & 3.19 & .62 & .12 \\
\hline Did not inform employer of loss & Ref & - & - & - & - \\
\hline \multicolumn{6}{|l|}{ Other workplace supports } \\
\hline Other supports offered & -3.38 & $(-9.72-2.95)$ & 3.23 & -.57 & .29 \\
\hline Other supports not offered & -3.78 & $(-10.19-2.63)$ & 3.27 & -.67 & .25 \\
\hline Did not inform employer of loss & Ref & - & - & - & - \\
\hline Extent of acknowledgement from healthcare professionals & -.46 & $(-0.84--0.08)$ & .20 & -.18 & .02 \\
\hline
\end{tabular}


Table 6 Multiple stepwise linear regression for instrumental grief $(n=210)$

\begin{tabular}{|c|c|c|c|c|c|}
\hline & $B$ & $95 \% \mathrm{Cl}$ & SE $B$ & $\beta$ & $p$ \\
\hline \multicolumn{6}{|l|}{ Variables } \\
\hline \multicolumn{6}{|l|}{ Loss focus } \\
\hline Ectopic pregnancy & -.91 & $(-3.8-1.99)$ & 1.48 & -.03 & .54 \\
\hline TOPFA & -.38 & $(-1.86-1.10)$ & .76 & -.04 & .62 \\
\hline Miscarriage & -1.12 & $(-2.43-0.20)$ & .67 & -.12 & .09 \\
\hline Stillbirth & .21 & $(-0.98-1.41)$ & .61 & .02 & .73 \\
\hline Neonatal death & Ref & - & - & - & - \\
\hline \multicolumn{6}{|l|}{ Ethnicity } \\
\hline Other & -.41 & $(-1.59-0.77)$ & .60 & .06 & .49 \\
\hline Australian & Ref & - & - & - & - \\
\hline PAAS Quality of Attachment subscale & -.15 & $(-0.30--0.01)$ & .07 & -.15 & .03 \\
\hline PAAS Time in Attachment subscale & .16 & $(0.04-0.27)$ & .06 & .17 & $<.01$ \\
\hline Age at loss (in years) & -.84 & $(-0.17-0.01)$ & .05 & -.12 & .06 \\
\hline Importance of religion & -.25 & $(-0.57-0.08)$ & .17 & -.11 & .13 \\
\hline Marital satisfaction at the time of loss & .43 & $(-0.40-1.26)$ & .42 & .07 & .31 \\
\hline Agreement to the statement: "My role following the loss was to support my partner and family" & .49 & $(-0.05-1.03)$ & .27 & .09 & .07 \\
\hline Agreement to the statement: "I was unable to grieve, because I was too busy supporting everyone else" & .51 & $(0.13-0.89)$ & .20 & .18 & $<.01$ \\
\hline CSS total score & -.08 & $(-0.16--0.01)$ & .04 & -.18 & .03 \\
\hline Acknowledgement of grief from partner & -.53 & $(-0.99--0.06)$ & .24 & -.17 & .03 \\
\hline Acknowledgement of grief from friends & .27 & $(-0.26-0.77)$ & .24 & .07 & .29 \\
\hline CMNI Self-Reliance subscale & .19 & $(0.03-0.34)$ & .08 & .16 & .02 \\
\hline MRNI Toughness subscale & .07 & $(-0.04-0.19)$ & .06 & .08 & .22 \\
\hline \multicolumn{5}{|l|}{ Workplace leave } & .09 \\
\hline Employment leave offered & -2.01 & $(-3.63--0.39)$ & .83 & -.14 & .02 \\
\hline Employment leave not offered & -2.25 & $(-3.98--0.52)$ & .89 & -.15 & .01 \\
\hline Did not inform employer of loss & Ref & - & - & - & - \\
\hline \multicolumn{5}{|l|}{ Perceived degree of inclusion in the hospital } & .33 \\
\hline High level of inclusion & -.103 & $(-1.39-1.18)$ & .66 & -.04 & .88 \\
\hline Low level of inclusion & -.48 & $(-1.82-0.85)$ & .68 & -.11 & .48 \\
\hline No contact with a hospital & Ref & - & - & - & - \\
\hline
\end{tabular}

role as a 'supporter' prevented them from grieving and experienced higher levels of acknowledgement from family also had higher grief scores; however, the precision of the strength of relationships for these factors was less certain. Men's grief scores also differed depending on the type of loss experienced; however, again, the extent to which loss type impacted grief scores was also less certain.

Factors associated with men's grief also differed depending on grief style. There was a high level of confidence that increased perceived support from healthcare professionals was associated with lower levels of intuitive grief. Results also indicated that viewing an ultrasound image of their baby during pregnancy, identifying with an ethnicity other than Australian, developing a higher quality of attachment to the baby during pregnancy, higher levels of overall social support, and lower endorsement of self-reliance could be relevant for intuitive grief. However, given the confidence intervals for these factors just crossed zero, further research is needed to confirm the direction of the associations. In relation to instrumental grief scores, men who had higher levels of social support, high quality of attachment to their baby during pregnancy, and acknowledgement of grief from their partner, had reduced instrumental grief. In contrast, perceptions of their supporter role interfering with their grief, higher tendencies toward self-reliance, as well as an increased amount of time spent bonding with their baby during pregnancy, were associated with higher levels of instrumental grief. Men who did not inform their workplace of their loss also had higher levels of instrumental grief than men who did, however the 
precision of these estimates was less certain. While it is possible that informing an employer leads to lower grief levels (e.g., through enhancing recognition of grief), this finding may also be reflective of the instrumental grief style itself, which typically involves coping in isolation and privacy [27].

These findings relating to grief styles imply that strategies to best support men may need to vary depending on men's grieving style. For example, intuitive grievers may benefit from higher levels of healthcare professional support and acknowledgement in the hospital, whereas instrumental grievers may benefit more from external social supports and higher levels of partner acknowledgement for their grief. This idea is in line with research on grief styles, which suggests that intuitive grievers more frequently access professional counselling services, whereas instrumental grievers rely on informal social supports [27, 86]. However, this is not to say that counselling is unsuitable for instrumental grievers. Rather, traditional counselling services may need to better target and support the unique needs of instrumental grievers and use tailored marketing strategies to increase their appeal/accessibility among men [86-88]. In addition, receiving adequate informal social supports may be a useful first step to providing recognition and validation to instrumental grievers, which could then lead to accessing more formal support services where required.

Although men who had experienced an early gestation loss (before 20 weeks) had the lowest average grief score, their scores still met the cut-off for a high degree of grief. Standard deviations also indicated a wide variation in scores across loss types, supporting the view than grief is a highly individualised experience, not necessarily dependent on the gestational age of the baby $[10,12,36]$. Overall, men who experienced later-gestation loss (including stillbirth and TOPFA after 20 weeks' gestation) had the highest average grief scores. Such high levels of grief may be related to both the unexpected nature of stillbirth, specific challenges associated with TOPFA, and with the stigma and disenfranchisement that many bereaved parents experience $[1,5-8,10,17,89,90]$. In comparison to a neonatal death, which may be due to known medical complications and managed through a Neonatal Intensive Care Unit (NICU), parents who experience stillbirth continue to report variation in care received and availability of support services [42, 91-94].

Men's role as a 'supporter' to their female partner has been a consistent finding across studies $[10,12,13,36$, $39,40,60]$. However, our findings suggest that this role in and of itself was not a substantial contributor to men's grief intensity. Instead, it was the extent to which men perceived the supporter role to interfere with their grieving that was significant, particularly for instrumental grievers. Assuming a supporter role is not necessarily a negative contributor to the grief experience but, where this role takes precedence over men's needs, it may become detrimental to their grief. It is therefore imperative that healthcare professionals are equipped to assist men to balance their desire and need to support their partner, while also addressing their grief and need for support. Healthcare professionals may assist men to achieve balance by not only providing them with tailored practical tips for supporting their partner but also acknowledging their grief and making efforts to provide active, ongoing support in the weeks/months following the loss.

In line with previous research, the degree of men's attachment to their baby during pregnancy was associated with grief $[10,16,36]$. Although viewing an ultrasound was associated with instrumental grief, broader measures of attachment, including both time in attachment and quality of attachment, had stronger associations with grief in general. These findings are in contrast to early research suggesting that viewing an ultrasound and attending obstetric appointments were the main drivers of men's attachment to a developing baby [24, 25, 37], demonstrating that many men develop a very early prenatal attachment to their baby.

Although the precision of the estimate was uncertain, one of the more unexpected findings was that higher levels of grief were associated with more acknowledgement from family. This relationship could be purely correlational, in that men who experienced higher grief sought more acknowledgement and support from family members. However, it could also be that although men received support from their family, the type of support received did not address their needs. For example, previous research suggests that although family members may be available to support men, the support may not be effective. Challenges to providing effective support reported by men have included a lack of understanding or unhelpful comments despite well-meaning intentions [10-12, 32, 95], feeling as though they needed to support their family members through their grief $[10,13,16,32,95,96]$, not feeling comfortable discussing their feelings with family members (where family referred to people other than their female partner) [12], and a desire for practical support (e.g., cooking, cleaning, childcare) as well as emotional support [16]. In line with research exploring the impact of pregnancy loss and neonatal death on extended family members including siblings and grandparents [97-101], this finding supports a family-centred approach to providing information and support for loss and grief, so that all family members involved in the experience of loss are better able to support one another.

\section{Strengths, limitations and future research}

Previous research involving bereaved parents has noted difficulties in representing men's perspectives, with 
female participants more often than not outweighing men $[7,9,93,101]$. This study is one of the largest samples of men to have been surveyed on their experiences of grief following pregnancy loss and neonatal death in Australia. In line with father-inclusive practice recommendations $[88,102]$, targeting the research directly for 'men/fathers' specifically, rather than 'parents' collectively, was a successful approach. However, although the sample is sizeable, the convenience nature of sampling is open to potential bias in that participants may have been unique from other men who chose not to participate. For example, one third of participants in this study had experienced four or more previous losses. Participants were also recruited through advertisements disseminated by Australian pregnancy loss and neonatal death support organisations. This recruitment approach could constitute a sampling bias in that men who were not connected to these organisations would not have had access to the information to participate.

High levels of internal consistency were observed for the majority of included measures. However, a low Cronbach's alpha was observed for the Toughness subscale of the MRNI. Although this measure of 'toughness' did not emerge as a significant predictor in any of the models in the current study, it may still be an important factor to consider, as a low alpha value may indicate that this measure did not adequately capture men's experiences of needing to be 'strong' or 'tough' as reported in previous qualitative studies [10, 12, 13, 31, 36]. Future research could explore alternative ways to measure this construct and assess whether it is important in explaining men's grief.

Although the majority of men reflected on losses within the last five years, this study relied on retrospective accounts of grief which may be open to recall bias, especially for the small number of losses which had occurred up to 20 years ago. Although we found no substantial differences in grief scores according to time since loss in our sample, changes in individual, community and health system/policy level support over time are likely to shape men's grief outcomes. For example, the Australian government recently announced policy changes to allow parents up to 12 months of unpaid leave following a stillbirth [103]. This change is a substantial step forward for recognition of parents' grief after stillbirth, and may ease the burden of grief on men. However, this research was conducted before these changes and future research is recommended to monitor trends in uptake and impact upon grief. Longitudinal studies which follow men during pregnancy and in the event of a pregnancy loss or neonatal death would be useful to identify the factors associated with grief at the time of loss, as well as to trial support services which may be useful.

The cultural diversity of the sample was also limited. Although men who identified as Australian had slightly higher levels of intuitive grief, no other associations were identified in relation to ethnicity. There is an ongoing and pressing need to examine the experiences of culturally and linguistically diverse men following pregnancy loss and neonatal death, as well as men in some countries where pregnancy and childbirth are still very much considered 'women's business' [33, 60, 104]. This is despite increasing evidence of the health benefits for both mother and baby when male partners are engaged in pregnancy and birth [104-108]. Finally, although this study was open to non-heterosexual men, only one participant identified as bisexual, and none as gay or transgender. Given research to suggest that gay and transgender men may face unique challenges concerning pregnancy, birth and loss [109-112], there is a need for research specifically targeting the experiences of these under-represented groups.

\section{Conclusions}

As this is one of the first studies to comprehensively explore multiple socioecological factors associated with men's grief following pregnancy loss and neonatal death, many of the findings are relatively novel and require further research to understand the causal pathways underlying relationships. However, what is clear is that men often experience significant grief following a pregnancy loss or neonatal death. There is a need to initiate and trial support interventions targeted specifically to men and designed with consideration for the factors associated with men's grief. Intervention strategies should engage individually with men both immediately in hospitals, and in the weeks/months following a loss, to ensure they have access to tailored support and services where these are needed. Intervention, particularly for intuitive grievers, could include formal brief assessment of men's grief and mental health in the hospital and in the weeks/months following discharge (e.g., the Edinburgh Postnatal Depression Scale). Intervention, particularly for instrumental grievers, could also involve providing a follow-up telephone service specifically to men postdischarge from the hospital including referral to community-based supports where required, or delivering couples-based psychoeducation sessions to foster positive communication, mutual understanding of individual grief styles and information on supporting one another. At the service level, an intervention could include delivering father-inclusive training to healthcare professionals who work with couples experiencing pregnancy loss and neonatal death. To best assist men, genuine acknowledgement and engagement of men as equal partners throughout pregnancy, and in loss and grief, is required. Taking a public health or socioecological approach to understanding grief will also be beneficial in identifying target areas for strategies in all areas of men's lives that may be affected by their grief. 


\section{Supplementary Information}

The online version contains supplementary material available at https://doi. org/10.1186/s12884-020-03514-6.

Additional file 1. Copy of the online survey.

\section{Abbreviations}

CMNI: Conformity to Masculine Norms Inventory; CSS: Crisis Support Scale; GPI: Grief Patterns Inventory; MRNI: Male Role Norms Inventory; NICU: Neonatal Intensive Care Unit; PAAS: Paternal Antenatal Attachment Scale; PGS: Perinatal Grief Scale; SD: Standard deviation; TOPFA: Termination of pregnancy for foetal anomaly

\section{Acknowledgements}

The authors would like to express their sincere thanks to the men who participated in the survey. Also to Suzanne Edwards for her assistance with data analysis, A/Prof Cass Dykeman for providing information on scoring the Grief Patterns Inventory, and the research reference group for their comprehensive feedback on survey development.

\section{Authors' contributions}

$\mathrm{KO}, \mathrm{MO}, \mathrm{CD}$ and PM were extensively involved in the development of the survey, including devising research questions, selection and development of included measures, piloting and revision to form the final survey. $\mathrm{KO}$ prepared the survey for online distribution and completed data cleaning and analysis, with the assistance of $\mathrm{MO} . \mathrm{KO}, \mathrm{MO}, \mathrm{CD}$ and PM contributed to organisation and presentation of the data and final results. $\mathrm{KO}$ wrote the paper and prepared the manuscript for journal submission; MO, CD and PM substantially contributed to editing the draft. All authors read and approved the final manuscript.

\section{Authors' information}

$\mathrm{KO}$ has a Bachelor of Psychology (First Class Honours) and is currently completing a combined PhD/Master of Health Psychology in the School of Psychology at the University of Adelaide. MO is a Lecturer in the School of Psychology, has a Masters of Psychology (Clinical and Health), a PhD in Psychology, and is a registered and endorsed Psychologist (Clinical and Health). CD is a Senior Lecturer in the School of Psychology and has a PhD in Psychology. PM is a perinatal epidemiologist with a Masters of Public Health and $\mathrm{a}$ PhD in Medicine.

\section{Funding}

KO is supported by an Australian Government Research Training Program Scholarship and a Westpac Scholars Trust Future Leaders Scholarship. The funding bodies played no role in the design of the study and collection, analysis, or interpretation of data or in writing the manuscript.

\section{Availability of data and materials}

The datasets generated and analysed during the current study are not publicly available as ethical consent was not obtained from participants to do so, and the data cannot be anonymised sufficiently for public sharing. The data may be available from the corresponding author on reasonable request.

\section{Ethics approval and consent to participate}

Ethical approval for the study was granted by the University of Adelaide Human Research Ethics Committee on the 5th of June, 2019 (approval code: HREC-2018-273). Detailed information about the study and informed consent was provided at the start of the online survey. After reading the study preamble, participants provided passive consent by choosing to commence the survey and submit their responses. This method of consent was approved by the University of Adelaide Human Research Ethics Committee.

\section{Consent for publication}

Not applicable.

\section{Competing interests}

The authors have no competing interests to declare.

\section{Author details}

${ }^{1}$ School of Psychology, University of Adelaide, Adelaide, South Australia. ${ }^{2}$ South Australian Health and Medical Research Institute, Adelaide, South Australia.

Received: 25 August 2020 Accepted: 21 December 2020

Published online: 07 January 2021

\section{References}

1. Burden C, Bradley S, Storey C, Ellis A, Heazel AEP, Downe S, et al. From grief, guilt pain and stigma to hope and pride - a systematic review and metaanalysis of mixed-method research of the psychosocial impact of stillbirth. BMC Pregnancy Childbirth. 2016;16:9.

2. Murphy S, Cacciatore J. The psychological, social, and economic impact of stillbirth on families. Semin Fetal Neonatal Med. 2017;22(3):129-34.

3. van den Akker OBA. The psychological and social consequences of miscarriage. Expert Rev Obstet Gynecol. 2011;6(3):295-304.

4. Mills TA, Ricklesford C, Cooke A, Heazell AEP, Whitworth M, Lavender T. Parents' experiences and expectations of care in pregnancy after stillbirth or neonatal death: a metasynthesis. BJOG. 2014;121(8):943-50.

5. Mulvihill A, Walsh T. Pregnancy loss in rural Ireland: an experience of disenfranchised grief. Br J Soc Work. 2014:44(8):2290-306.

6. Lang A, Fleiszer AR, Duhamel F, Sword W, Gilbert KR, Corsini-Munt S. Perinatal loss and parental grief: the challenge of ambiguity and disenfranchised grief. OMEGA J Death Dying. 2011;63(2):183-96.

7. Pollock D, Pearson E, Cooper M, Ziaian T, Foord C, Warland J. Voices of the unheard: a qualitative survey exploring bereaved parents' experiences of stillbirth stigma. Women Birth. 2019;33(2):165-74.

8. Brierley-Jones L, Crawley R, Lomax S, Ayers S. Stillbirth and stigma: the spoiling and repair of multiple social identities. OMEGA J Death Dying. 2015;70(2):143-68

9. Kelley MC, Trinidad SB. Silent loss and the clinical encounter: Parents' and physicians' experiences of stillbirth - a qualitative analysis. BMC Pregnancy Childbirth. 2012;12:137.

10. Obst KL, Due C. Australian men's experiences of support following pregnancy loss: a qualitative study. Midwifery. 2019;70:1-6.

11. Miller EJ, Temple-Smith MJ, Bilardi J. There was just no-one there to acknowledge that it happened to me as well': A qualitative study of male partner's experience of miscarriage. PLoS One. 2019;14(5):e0217395.

12. McCreight BS. A grief ignored: narratives of pregnancy loss from a male perspective. Sociol Health IIIn. 2004;26(3):326-50.

13. Bonnette $S$, Broom A. On grief, fathering and the male role in men's accounts of stillbirth. J Sociol. 2011;49(3):249-65.

14. Chavez MS, Handley V, Jones RL, Eddy B, Poll V. Men's experiences of miscarriage: a passive phenomenological analysis of online data. J Loss Traum. 2019;27(7):664-77.

15. Pabón L, Fergusson MEM, Palacios AM. Experience of perinatal death from the father's perspective. Nurs Res. 2019;68(5):E1-9.

16. Wagner NJ, Vaughn CT, Tuazon VE. Fathers' lived experiences of miscarriage Fam J. 2018;26(2):193-9.

17. Riggs DW, Due C, Tape N. Australian heterosexual men's experiences of pregnancy loss: the relationships between grief, psychological distress, stigma, help-seeking, and support. OMEGA J Death Dying. 2018;82(3): 40923.

18. Alderman L, Chisholm J, Denmark F, Salbod S. Bereavement and stress of a miscarriage: as it affects the couple. OMEGA J Death Dying. 1998;37(4):317-27.

19. Volgsten H, Jansson C, Svanberg AS, Darj E, Stavreus-Evers A. Longitudinal study of emotional experiences, grief and depressive symptoms in women and men after miscarriage. Midwifery. 2018;64:23-8.

20. Cope H, Garrett ME, Gregory S, Ashley-Koch A. Pregnancy continuation and organizational religious activity following prenatal diagnosis of a lethal fetal defect are associated with improved psychological outcome. Prenat Diagn. 2015;35(8):761-8.

21. Serrano F, Lima ML. Recurrent miscarriage: psychological and relational consequences for couples. Psychol Psychother Theory Res Pract. 2006;79(4): 585-94.

22. Rich DE. The impact of postpregnancy loss services on grief outcome: integrating research and practice in the design of perinatal bereavement. IIIn Crisis Loss. 2000;8(3):224-64. 
23. Huffman CS, Schwartz TA, Swanson KM. Couples and miscarriage: the influence of gender and reproductive factors on the impact of miscarriage. Womens Health Issues. 2015;25(5):570-8.

24. Puddifoot JE, Johnson MP. The legitimacy of grieving: the partner's experience at miscarriage. Soc Sci Med. 1997;46(6):837-45.

25. Johnson MP, Puddifoot JE. The grief response in the partners of women who miscarry. Br J Med Psychol. 1996;69:313-27.

26. Conway K, Russell G. Couples' grief and experience of support in the aftermath of miscarriage. Br J Med Psychol. 2000;73(4):531-45.

27. Doka KJ, Martin T. Grieving beyond gender: understanding the ways men and women mourn. New York: Routledge; 2010

28. Avelin P, Rådestad I, Säflund K, Wredling R, Erlandsson K. Parental grief and relationships after the loss of a stillborn baby. Midwifery. 2013;29(6):668-73.

29. Weaver-Hightower MB. Waltzing Matilda: an autoethnography of a father's stillbirth. J Contemp Ethnogr. 2012;41(4):462-91.

30. Armstrong D. Exploring fahters' experiences of pregnancy after a prior perinatal loss. MCN Am J Matern Child Nurs. 2001;26(3):147-53.

31. Jones K, Robb M, Murphy S, Davies A. New understandings of fathers' experiences of grief and loss following stillbirth and neonatal death: a scoping review. Midwifery. 2019;79:102531.

32. Murphy F. The experience of early miscarriage from a male perspective. J Clin Nurs. 1998;7(4):325-32.

33. O'Leary J, Thorwick C. Fathers' perspectives during pregnancy, postperinatal loss. J Obstet Gynecol Neonatal Nurs. 2006;35(1):78-86.

34. Samuelsson M, Rådestad I, Segesten K. A waste of life: fathers' experience of losing a child before birth. Birth. 2001;28(2):124-30.

35. Johnson MP, Baker SR. Implications of coping repertoire as predictors of men's stress, anxiety and depression following pregnancy, childbirth and miscarriage: a longitudinal study. J Psychosom Obstet Gynecol. 2004;25:8798.

36. Obst $\mathrm{KL}$, Due C, Oxlad M, Middleton P. Men's grief following pregnancy loss and neonatal loss: a systematic review and emerging theoretical model. BMC Pregnancy Childbirth. 2020;20:11

37. Puddifoot JE, Johnson MP. Active grief, despair, and difficulty coping: some measured characteristics of male response following their partner's miscarriage. J Reprod Infant Psychol. 1999;17(1):89-93.

38. Franche RL. Psychologic and obstetric predictors of couples' grief during pregnancy after miscarriage or perinatal death. Obstet Gynecol. 2001;97(4): 597-602.

39. Cacciatore J, Erlandsson K, Rådestad I. Fatherhood and suffering: a qualitative exploration of Swedish men's experiences of care after the death of a baby. Int J Nurs Stud. 2013;50(5):664-70.

40. Miron J, Chapman JS. Supporting: Men's experiences with the event of their partners' miscarriage. Can J Nurs Res. 1994;26(2):61-72.

41. Hamama-Raz Y, Hemmendinger S, Buchbinder E. The unifying difference: dyadic coping with spontaneous abortion among religious Jewish couples. Qual Health Res. 2010;20(2):51-61.

42. Farrales LL, Cacciatore J, Jonas-Simpson C, Dharamsi S, Ascher J, Klein MC. What bereaved parents want health care providers to know when their babies are stillborn: a community-based participatory study. BMC Psychol. 2020;8:18

43. Bennett SM, Litz BT, Maguen S, Ehrenreich JT. An exploratory study of the psychological impact and clinical care of perinatal loss. J Loss Trauma. 2008; 13:485-510.

44. Cacciatore J, Frøen J, Killian M. Condemning self, condemning other: blame and mental health in women suffering stillbirth. J Mental Health Couns. 2013;35(4):342-59.

45. Janssen HJEM, Cuisinier MCJ, de Graauw KPHM, Hoogduin KAL. A prospective study of risk factors predicting grief intensity following pregnancy loss. Arch Gen Psychiatry. 1997;54(1):56-61.

46. Engler AJ, Lasker JN. Predictors of maternal grief in the year after a newborn death. IIIn Crisis Loss. 2000;8(3):227-43.

47. Hunfeld JAM, Wladimiroff JW, Verhage F, Passchier J. Previous stress and acute psychological defence as predictors of perinatal grief - an exploratory study. Soc Sci Med. 1995;40(6):829-35.

48. Lafarge C, Mitchell K, Fox P. Perinatal grief following a termination of pregnancy for foetal abnormality: the impact of coping strategies. Prenat Diagn. 2013;33:1173-82.

49. Mann JR, McKeown RE, Bacon J, Vesselinov R, Bush F. Predicting depressive symptoms and grief after pregnancy loss. J Psychosom Obset Gynecol. 2008;29(4):274-9.
50. McSpedden M, Mullan B, Sharpe L, Breen L, Lobb EA. The presence and predictors of complicated grief symptoms in perinatally bereaved mothers from a bereavement support organization. Death Stud. 2017;41(2):112-7.

51. Nazaré B, Fonseca A, Canavarro MC. Adaptive and maladaptive grief responses following TOPFA: actor and partner effects of coping strategies. J Reprod Infant Psychol. 2013;31(3):257-73.

52. Barr P. Guilt- and shame-proneness and the grief of perinatal bereavement. Psychol Psychother Theory Res Pract. 2004;77(4):493-510.

53. Barr P. Negative self-conscious emotion and grief: an actor-partner analysis in couples bereaved by stillbirth or neonatal death. Psychol Psychother Theory Res Pract. 2012;85:310-26.

54. Breeze C. Early pregnancy bleeding. Aust Fam Physician. 2016;45(5):283-6.

55. Hajenius PJ, Mol F, Mol BWJ, Bossuyt PMM, Ankum WM, Van der Veen F. Interventions for tubal ectopic pregnancy (review). Cochrane Database Syst Rev. 2007:1:CD000324

56. Goksedef BPC, Kef S, Akca A, Bayik RNE, Cetin A. Risk factors for rupture in tubal ectopic pregnancy: definition of the clinical findings. Europ J Obstet Gynecol Reprod Biol. 2010;154(1):96-9.

57. Australian Institute of Health and Welfare. Stillbirths and neonatal deaths in Australia. Canberra: AlHW; 2020. (Cat. no: PER 107).

58. Consultative Council on Obstetric and Paediatric Mortality and Morbidity. Congenital anomalies in Victoria 2015-2016. Melbourne: Safer Care Victoria; 2017.

59. Victorian Law Reform Commission. Law of abortion: final report. Melbourne: VLRC; 2008.

60. Due C, Chiarolli S, Riggs DW. The impact of pregnancy loss on men's health and wellbeing: a systematic review. BMC Pregnancy Childbirth. 2017;17:380.

61. Condon J, Corkindale C, Boyce P, Gamble E. A longitudinal study of fatherto-infant attachment: antecedents and correlates. J Reprod Infant Psychol. 2013:31(1):15-30.

62. Condon J. The assessment of antenatal emotional attachment: development of a questionnaire instrument. Br J Med Psychol. 1993;66:16383

63. Habib C, Lancaster S. Changes in identity and paternal-foetal attachment across a first pregnancy. J Reprod Infant Psychol. 2010;28:128-42.

64. Seimyr L, Sjögren B, Welles-Nyström B, Nissen E. Antenatal maternal depressive mood and parental-foetal attachment at the end of pregnancy. Arch Womens Ment Health. 2009;12:269-79.

65. Potvin L, Lasker J, Toedter L. Measuring grief: a short version of the perinatal grief scale. J Psychopathol Behav Assess. 1989;11(1):29-45.

66. Toedter L, Lasker JN, Janssen HJEM. International comparison of studies using the perinatal grief scale: a decade of research on pregnancy loss. Death Stud. 2001;25(3):205-28

67. Lasker J, Toedter L. Predicting outcomes after pregnancy loss: results from studies using the perinatal grief scale. IIIn Crisis Loss. 2000;8(4):350-72.

68. Martin TL, Wang W. A pilot study of the development of a tool to measure instrumental and intuitive styles of grieving. OMEGA J Death Dying. 2006; 53(4):263-76.

69. Lange R, Dykeman C, Beckett C. Grieving styles of young Banso widows. OMEGA J Death Dying. 2018;81(3):493-506.

70. Gamino LA, Sewell KW, Prosser-Dodds L, Hogan NS. Intuitive and instrumental grief: a study of the reliability and validity of the grief pattern inventory. OMEGA J Death Dying. 2018;81(4):532-50.

71. Elklit A, Pedersen SS, Jind L. The crisis support scale: psychometric qualities and further validation. Pers Individ Differ. 2001:31(8):1291-302.

72. Mahalik JR, Locke BD, Ludlow LH, Diemer MA, Scott RPJ, Gottfried M, Freitas G. Development of the conformity to masculine norms inventory. Psychol Men Masc. 2003;4(1):3-25

73. Thompson EH, Bennett KM. Measurement of masculinity ideologies: a (critical) review. Psychol Men Masc. 2015;16(2):115-33.

74. Levant RF, et al. The male role: an investigation of norms. J Ment Health Couns. 1992;14(3):325-37.

75. Levant RF, Hall RJ, Rankin TJ. Male role norms inventory-short form (MRNISF): development, confirmatory factor analytic investigation of structure, and measurement invariance across gender. J Couns Psychol. 2013;60(2): 228-38.

76. Sainani KL. Explanatory versus predictive modeling. PM R. 2014;6(9):841-4.

77. Nelder J, Wedderburn R. Generalized linear models. J Royal Stat Soc. 1972; 135(3):370-84

78. Harrell FE. Multivariable modeling strategies. In: Regression Modeling Strategies. New York: Springer; 2015. p. 63-102. 
79. Smith G. Step away from stepwise. J Big Data. 2018;5(1):32.

80. Mundry R, Nunn CL. Stepwise model fitting and statistical inference: turning noise into signal pollution. Am Nat. 2009;173(1):119-23.

81. Bonett DG, Wright TA. Sample size requirements for multiple regression interval estimation. J Organ Behav. 2011;32(6):822-30.

82. Combs JG. Big samples and small effects: Let's not trade relevance and rigor for power. Acad Manag J. 2010;53:9-13.

83. Harris RJ. A primer of multivariate statistics. New York: Academic Press; 1975.

84. Nunnally J. Psychometric theory. 2nd ed. New York: McGraw-Hill; 1978.

85. Tabachnick BG, Fidell LS. Using multivariate statistics. 6th ed. New Jersey: Pearson Education; 2013.

86. Doka KJ, Martin T. Grieving styles: gender and grief. Grief Matters Aust J Grief Bereavement. 2011;14(2):42-5.

87. Seidler Z, Rice SM, Ogrodniczuk JS, Oliffe JL, Dhillon HM. Engaging men in psychological treatment: a scoping review. Am J Mens Health. 2018;12(6): 1882-900.

88. Fletcher R. Bringing fathers in handbook: how to engage with men for the benefit of everyone in the family. Newcastle: Family Action Centre, University of Newcastle; 2004

89. Kersting A, Wagner B. Complicated grief after perinatal loss. Dialogues Clin Neuro. 2012;14(2):187-94.

90. Nazaré B, Fonesca A, Canavarro MS. Trauma following termination of pregnancy for fetal abnormality: is this the path from guilt to grief? J Loss Trauma. 2014;19(3):244-61.

91. Basile ML, Thorsteinsson EB. Parents' evaluation of support in Australian hospitals following stillbirth. PeerJ. 2015;3:e1049.

92. Downe S, Schmidt E, Kingdon C, Heazell AEP. Bereaved parents' experience of stillbirth in UK hospitals: a qualitative interview study. BMJ Open. 2013; 3(2):e002237.

93. King $M Q$, Oka M, Robinson D. Pain without reward: a phenomenological exploration of stillbirth for couples and their hospital encounter. Death Stud. 2019.

94. Ellis A, Chebsey C, Storey C, Bradley S, Jackson S, Flenady V, et al. Systematic review to understand and improve care after stillbirth: a review of parents' and healthcare professionals' experiences. BMC Pregnancy Childbirth. 2016; 16:16.

95. Hortsman HK, Holman A, McBride MC. Men's use of metaphors to make sense of their spouse's miscarriage: expanding the communicated sensemaking model. Health Comm. 2020;35(5):538-47.

96. Sun JC, Rei W, Chang MY, Sheu SJ. The experiences of fathers whose spouses are hospitalized for pregnancy termination due to fetal chromosome abnormality in Taiwan. The J Nurs Res. 2018;26(4):297-305.

97. Murphy S, Jones KS. By the way knowledge: grandparents, stillbirth and neonatal death. Hum Fertil. 2014;17(3):210-3.

98. Lockton J, Due C, Oxlad M. Love, listen and learn: grandmothers' experiences of grief following their child's pregnancy loss. Women Birth. 2019;33(4):401-7.

99. Avelin P, Erlandsson K, Hildingsson I, Bremborg AD, Rådestad I. Make the stillborn baby and the loss real for the siblings: Parents' advice on how the siblings of a stillborn baby can be supported. J Perinat Educ. 2012;21(2):908.

100. Erlandsson K, Avelin P, Säflund K, Wredling R, Rådestad I. Siblings' farewell to a stillborn sister or brother and parents' support to their older children: a questionnaire study from the parents' perspective. J Child Health Care. 2010; 14(2):151-60.

101. Wilson PA, Boyle FM, Ware RS. Holding a stillborn baby: the view from a specialist perinatal bereavement service. Aust NZ J Obstet Gynacol. 2015; 55(4):337-43.

102. Panter-Brick C, Burgess A, Eggerman M, McAllister F, Pruett K, Leckman JF. Practitioner review: engaging fathers - recommendations for a game change in parenting interventions based on a systematic review of the global evidence. J Child Psychol Psychiat. 2014;55(11):1187-212.

103. Obst KL, Due C, Oxlad M, Middleton P. Australian men's experiences of leave provisions and workplace support following pregnancy loss or neonatal death. Community Work Fam. 2020.

104. Maken ZH, Idrees IN, Zahid A, Zulfiqar A, Munib A, Hassan F, Mahmood R. Factors influencing father's antenatal and perinatal involvement in maternal health care. J Matern-Fetal Neo Med. 2018;31(19):2569-75.

105. Redshaw M, Henderson J. Fathers' engagement in pregnancy and childbirth: evidence from a national survey. BMC Pregnancy Childbirth. 2013;13:70.
106. Tokhi M, Comrie-Thomson L, Davis J, Portela A, Chersich M, Stanley L. Involving men to improve maternal and newborn health: a systematic review of the effectiveness of interventions. PLoS One. 2018;13(1):e0191620.

107. Rahman AE, Perkins J, Salam SS, Mhajabin S, Hossain AT, Mazumder T, Arifeen S. What do women want? An analysis of preferences of women, involvement of men, and decision-making in maternal and newborn health care in rural Bangladesh. BMC Pregnancy Childbirth. 2020;20:169.

108. Comrie-Thomson L, Tohki M, Ampt F, Portela A, Chersich M, Khanna R, Luchters $S$. Challenging gender inequity through male involvement in maternal and newborn health: critical assessment of an emerging evidence base. Cult Health Sex. 2015;17:177-89.

109. Ziv I, Freund-Eschar Y. The pregnancy experience of gay couples expecting a child through overseas surrogacy. Family J. 2015;23(2):158-66.

110. Charter R, Ussher JM, Perz J, Robinson K. The transgender parent: experiences and constructions of pregnancy and parenthood for transgender men in Australia. Int J Transgenderism. 2018;19(1):64-77.

111. Hoffkling A, Obedin-Maliver J, Sevelius J. From erasure to opportunity: a qualitative study of the experiences of transgender men around pregnancy and recommendations for providers. BMC Pregnancy Childbirth. 2017;17: 332.

112. Ellis SA, Wojnar DM, Pettinato M. Conception, pregnancy, and birth experiences of male and gender variant gestational parents: it's how we could have a family. Midwifery Womens Health. 2015;60(1):62-9.

\section{Publisher's Note}

Springer Nature remains neutral with regard to jurisdictional claims in published maps and institutional affiliations.

\section{Ready to submit your research? Choose BMC and benefit from:}

- fast, convenient online submission

- thorough peer review by experienced researchers in your field

- rapid publication on acceptance

- support for research data, including large and complex data types

- gold Open Access which fosters wider collaboration and increased citations

- maximum visibility for your research: over $100 \mathrm{M}$ website views per year

At BMC, research is always in progress.

Learn more biomedcentral.com/submissions 